\title{
Hospitalisation for Bipolar Disorder: Comparison between Young and Elderly Patients
}

\author{
Isabelle Rouch ${ }^{1,2 *}$, Claude Marescaux ${ }^{3}$, Catherine Padovan ${ }^{4,5}$, Thierry D'Amato ${ }^{4,6}$, \\ Benoit Saitta ${ }^{3}$, Bernard Laurent ${ }^{1}$, Romain Rey4, Alexis Lepetit ${ }^{2,4}$, Jean Michel Dorey ${ }^{4}$ \\ ${ }^{1}$ Neurology Unit, University Hospital of Saint-Etienne, Saint Etienne, France \\ ${ }^{2}$ Geriatrics Unit, Charpennes Hospital, University Hospital of Lyon, Villeurbanne, France \\ ${ }^{3}$ Département d'Information Médicale, Vinatier Hospital, Bron, France \\ ${ }^{4}$ Memory Center-Gerontopsychiatry Unit, Vinatier Hospital, Bron, France \\ ${ }^{5}$ Brain Dynamics and Cognition Team, Lyon Neurosciences Research Center, \\ Bron, France \\ ${ }^{6}$ Université Lyon 1, Lyon, France \\ Email: ${ }^{*}$ isabelle.rouch@chu-st-etienne.fr
}

Received 2 January 2015; accepted 21 January 2015; published 26 January 2015

Copyright (C) 2015 by authors and Scientific Research Publishing Inc.

This work is licensed under the Creative Commons Attribution International License (CC BY).

http://creativecommons.org/licenses/by/4.0/

(c) (i) Open Access

\section{Abstract}

Although Bipolar Disorder (BD) often affects young subjects, the number of elderly patients suffering from BD is rising as life expectancy increases. Few studies addressed the hospitalisation characteristics according to patient age. The goal of this preliminary study was to compare the hospitalisation characteristics of young and elderly patients suffering from BD admitted in a psychiatric hospital. The data were selected from the French nation-wide hospital database for psychiatry. The study included patients hospitalised in a French psychiatric hospital from January 2002 to December 2012. The hospitalisation characteristics were compared between young (YBD) and elderly bipolar patients (EBD). A total of 1842 patients were hospitalised during the 11-year period. Among them, 707 (38.4\%) were 60 years old and over. The mean length of stay was significantly longer for the EBD group than for the YBD group (48.1 vs 30.4 days, $p<0.0001)$. Among the patients first hospitalised in 2002, the readmission rate was significantly higher for the EBD $(67.9 \%)$ than for the YBD $(55.2 \%)$ group ( $p=0.026)$. In contrast, the rate of compulsory hospitalisations was higher among the YBD than among the EBD group. Our findings confirm that BD in old age remains a severe disease requiring longer hospitalisations than for BD in younger patients. Future prospective studies are needed to better understand the origin of these differences.

${ }^{*}$ Corresponding author.

How to cite this paper: Rouch, I., Marescaux, C., Padovan, C., D'Amato, T., Saitta, B., Laurent, B., Rey, R., Lepetit, A., \& Dorey, J. M. (2015). Hospitalisation for Bipolar Disorder: Comparison between Young and Elderly Patients. Psychology, 6, 126131. http://dx.doi.org/10.4236/psych.2015.61011 


\section{Keywords}

\section{Bipolar Disorder, Elderly, Hospitalisation}

\section{Introduction}

Bipolar disorder (BD) can be defined as a chronic mental illness characterized by alternance of depression, mania or hypomania, euthymic or mixed states (Bauer et al., 2002; Oostervink et al., 2009). Its lifetime prevalence is estimated at about 3\%, varying from $0.2 \%$ to $6 \%$ in the European population (Pini et al., 2005). The first episode mostly occurs before the age of 30 . Almost $90 \%$ of BD patients had a first episode before the age of 50 (Hirschfeld et al., 2003; Oostervink et al., 2009). Although BD often concerns young subjects, the number of elderly patients suffering from BD is rising as life expectancy increases (Sajatovic et al., 2004).

The clinical evolution of BD with aging is a recent subject of interest but current knowledge is still sparse, with inconsistent results suggesting the heterogeneity of the disorder. Previous authors have observed more severe mania (Cassano et al., 2000) and more psychotic features (Oostervink et al., 2009) in young patients, but others show only small differences between age groups (Depp et al., 2004). Few studies addressed the characteristics of hospitalisations according to patient age. The most comprehensive one was lead by Oostervink in 2009 and reported no difference in hospitalisation rate between elderly and young patients (Oostervink et al., 2009).

The aim of this preliminary study was to compare the characteristics of hospitalisation of young and elderly patients with BD admitted in a University psychiatric hospital.

\section{Methods}

\subsection{French Hospital Database RIM-P}

The data were selected from French computerised hospital database for psychiatry (RIM-P: recueil d'information médicalisé en psychiatrie/Medical Psychiatric Data Collecting System). This database covers all hospitalisations in French psychiatry units. At each patient discharge, it includes a case record compiling administrative and medical data with standardised classifications and nomenclatures.

\subsection{Patients}

The study included patients hospitalised at University Vinatier psychiatric hospital, located in Lyon, from $1^{\text {rst }}$ of January 2002 to $31^{\text {th }}$ December 2012. Its catchment area covers a population of 800,000 inhabitants. Only new admissions after $1^{\text {st }}$ of January 2002 were considered in the present study. The present analysis was limited to patients admitted for BD as defined by the Tenth Edition of the International Classification of Diseases (World Health Organization, 1992). Manic episode (F 30.) or Bipolar Affective Disorders (F 31.) were included. The patients were divided into two groups according to their age at first admission at the Vinatier hospital: the young BD group (YBD) comprised of patients up to 59 years old, and the elderly BD group (EBD) included patients above the age of 60 .

\subsection{Assessment Variables}

The variables concerning characteristics of hospitalisation were mean Length of hospital Stay (LOS) in days, number of days of hospitalisation, number of days in isolation room and the use of compulsory hospitalisation legal measures admission. Compulsory placement concerns patients presenting a serious danger for themselves or other people. LOS was first treated as a quantitative variable, and then stratified into short ( $<15$ days), medium (14 - 28 days), long (29 - 42 days) and prolonged hospitalisation ( $>42$ days). These variables were compared between the YBD and the EBD groups. Percentage of annual days of hospitalisation and compulsory hospitalisation were then compared between the two groups. Finally, the percentage of days in an isolation room was compared between the two groups among patients having been hospitalised at least once with compulsory measures. A subsample of patients hospitalised in 2002 has then been isolated to determine the eleven-year hos- 
pitalisation rate.

\subsection{Statistical Analysis}

The sample was described using percentage for categorical variables. Means and standard deviation were used for quantitative variables. The comparison between young and elderly subjects was made using Pearson's Chi 2 for qualitative variables and ANOVA for quantitative variables. Non parametric tests (Chi 2 for qualitative variables or Mann Whitney U test for quantitative variables) were used when appropriate.

Multivariate analysis were then made using logistic regression models to assess the relationship between each hospitalisation variable (number of hospitalisation per year, mean LOS, stratified LOS, presence of compulsory hospitalisation, presence of seclusion during hospitalisation) and age of first hospitalisation (YBD versus EBD), taking into account gender as a confusion variable.

\section{Results}

A total of 1842 BP patients were hospitalised from January 2002 to December 2012 at Vinatier Hospital. Among them, 1135 (61.6\%) were under 60 years old and 707 (38.4\%) were 60 years old and over. The percentage of women was higher in the EBD group.

Demographic and hospitalisation characteristics by age group are given in Table 1 . The percentage of women was significantly lower in the YBD group than in the EBD group. The mean annual number of hospitalisations and days of hospitalisation were higher in the EBD group than in the YBD one. Moreover, the mean LOS was significantly longer for EBD group than for YBD one. Short stay (LOS $<14$ days) was significantly more frequent in YBD than in EBD group. In contrast, prolonged stay (LOS $>42$ days) was more frequent in EBD than in YBD.

Table 1. Comparison of young and elderly patients with bipolar disorder hospitalised in a psychiatric hospital between January 2002 and December 2012.

\begin{tabular}{|c|c|c|c|c|}
\hline & $\begin{array}{l}\text { Patients }<60 \text { years } \\
\quad N=1135\end{array}$ & $\begin{array}{c}\text { Patients } \geq 60 \text { years } \\
N=707\end{array}$ & $\begin{array}{c}\text { Total } \\
\mathrm{N}=1842\end{array}$ & $P$ value \\
\hline $\begin{array}{c}\text { Age } \\
\text { Mean (SD) }\end{array}$ & 43.8 (9.8) & 73.1 (9.5) & $55.0(17.2)$ & $<0.0001^{\mathrm{a}}$ \\
\hline $\begin{array}{l}\text { Age of first hospitalisation } \\
\text { Mean (SD) }\end{array}$ & $37.4(9.6)$ & $65.3(9.7)$ & 48.1 (16.6) & $<0.0001^{\mathrm{a}}$ \\
\hline $\begin{array}{l}\text { Gender } \\
\text { (\% women) }\end{array}$ & 605 (53.3) & 441 (62.4) & 1046 (56.8) & $<0.0001^{\text {b }}$ \\
\hline $\begin{array}{l}\text { Number of hospitalisations per year } \\
\text { Mean (SD) }\end{array}$ & $0.18(0.18)$ & $0.24(0.26)$ & $0.21(0.22)$ & $<0.0001^{\mathrm{a}}$ \\
\hline $\begin{array}{l}\text { Number of days of hospitalisations per year } \\
\text { Mean (SD) }\end{array}$ & $6.47(14.6)$ & $12.50(21.40)$ & 8.96 (17.95) & $<0.0001^{\mathrm{a}}$ \\
\hline $\begin{array}{l}\text { Length of stay (days) } \\
\text { Mean (SD) }\end{array}$ & $30.4(47.4)$ & 48.1 (65.3) & $37.0(55.4)$ & $<0.0001^{\mathrm{a}}$ \\
\hline \multicolumn{5}{|l|}{$\begin{array}{l}\text { Length of stay (days) } \\
\text { N (\%) }\end{array}$} \\
\hline$<14$ & 338 (33.6) & 112 (18.7) & $450(28.1)$ & \multirow{4}{*}{$<0.0001^{\mathrm{b}}$} \\
\hline 14 to 28 & 322 (32) & 135 (22.6) & 457 (28.5) & \\
\hline 29 to 42 & 159 (15.8) & 138 (23.1) & 297 (18.5) & \\
\hline$>42$ & $186(18.5)$ & 213 (35.6) & 399 (24.9) & \\
\hline $\begin{array}{l}\text { At least one compulsory hospitalisation } \\
\text { (\%) }\end{array}$ & $681(60.0)$ & 338 (47.8) & 1019 (55.3) & $<0.0001^{\mathrm{b}}$ \\
\hline $\begin{array}{l}\text { At least one seclusion during an hospitalisation }{ }^{c} \\
\text { (\%) }\end{array}$ & 232 (34.1) & 73 (21.6) & 305 (29.9) & $<0.0001^{\text {b }}$ \\
\hline
\end{tabular}

${ }^{\mathrm{a}}$ ANOVA test; ${ }^{\mathrm{b}}$ Pearson Chi 2 test; ${ }^{\mathrm{c}}$ among patients with at least one compulsory hospitalisation. 
The percentage of patients with at least one compulsory hospitalisation was compared between the YBD and EBD groups. The rate of patients with compulsory hospitalisation was higher among YBD than among EBD group. Among patients with at least one compulsory hospitalisation, the percentage of patients hospitalised in an isolation room was higher in YBD than in EBD one.

Furthermore, among the patients first hospitalised in 2002, 180 (61.2\%) had at least one readmission during the following eleven years. Among them, there were 95 YBD (55.2\%) and 85 EBD patients (67.9\%) The readmission rate was significantly higher for YBD than for EBD group $(p=0.026)$.

When using the multivariate logistic regression model, the relationship between each of the hospitalization variables and age of first hospitalisation (YBD versus EBD) remained significant [number of hospitalisation per year: OR $=1.02$ (CI: 1.02 - 1.03), $p<0.0001$; mean LOS: OR = 3.06 (CI: 2.56 - 3.67), $p<0.0001$; stratified LOS: OR $=1.56$ (CI: $1.42-1.71), p<0.0001$; presence of compulsory hospitalisation: $\mathrm{OR}=0.61$ (CI: 0.50 0.74), $p<0.0001$; presence of seclusion during hospitalisation: $\mathrm{OR}=0.55$ (CI: $0.40-0.74$ ), $p<0.0001$ )].

\section{Discussion}

The present study described the hospitalisation characteristics of patients admitted for bipolar disorders in a psychiatric hospital, and compared young and elderly patients. About $40 \%$ of them were 60 years old and over. This result highlights a higher prevalence of elderly patients hospitalised for BD than expected (Sajatovic et al., 2004). It could be explained both by a better treatment strategy in bipolar disorders and an increasing life expectancy.

Among the patients first hospitalised in 2002, 39\% had no readmission during the eleven following years. This result is in line with the findings of previous studies. In Sweeden, Ösby et al. reported that $56 \%$ of patients hospitalised in Sweden for bipolar disorders had no readmission in the five following years (Osby et al., 2009). Coryell et al. showed that $41 \%$ to $57 \%$ of BD patients had a favourable outcome, without hospital readmissions (Coryell et al., 1998). After an eleven-year follow-up, the risk of hospital readmission was more important for elderly patients than for younger patients. This higher rate of hospitalisation could be explained not only by acute psychiatric symptoms but also by medical comorbidities with misleading psychiatric presentation.

The mean LOS per hospitalisation was longer in our study than in two French (20.4 days) and Spanish (18.1 days) populations (Gonzalez-Pinto et al., 2010). In contrast, our results are in line with the findings of Osby et al., observing a LOS of 29.9 days for manic episodes and 42.3 for mixed episodes in a 50.4-year-old population. In an average 37.5-year-old population, Wu et al. reported a LOS of 29.0 days in bipolar patients without intellectual disabilities. Altogether, our findings and those of previous studies suggest that age is a major determinant of patients LOS. Our results show that elderly patients spend proportionally less time than young ones in compulsory hospitalisation and in isolation room. While no previous study confronted the hospitalisation data of young and elderly BD patients, previous authors compared the clinical characteristics of these two populations. Psychotic features were more frequent in young than elderly patients in two previous studies (Kessing 2006; Oostervink et al., 2009), as well suicide attempts (Oostervink et al., 2009). Furthermore, mania in the elderly was showed to be less severe than in young patients (Blackburn et al., 1977). These findings can enlighten our results reporting a higher rate of compulsory hospitalisation or hospitalisation in isolation room for younger patients. Conversely, elderly patients had an overall longer hospitalisation LOS, possibly explained by a higher rate of medical comorbidities (Sajatovic et al., 2005), the presence of cognitive impairment (Gildengers et al., 2004), the lack of social support and also higher caregiver stress (Oostervink et al., 2009). Finally, other features, such as waiting for a place in residential home or equivalent, could explain a higher LOS for elderly patients. In contrast, hospitalization is known to have side effects in the elderly, especially those with cognitive impairment (Wu et al., 2006).

A number of further limitations should be mentioned. Firstly, our data are retrospective, and limited to the hospitalisations at the Vinatier hospital. The data concerning rehospitalisations in other hospitals were not considered in the present analysis, and can underestimate our results. Nevertheless in France the psychiatric hospitalisation depends on the patient's address, so patients are supposed to be always taken care in the same psychiatric ward. The second limitation is the absence of information about the clinical characteristics of patients, their concomitant medical conditions, their cognitive status and their treatments. It would be interesting to confront these clinical data to hospitalisations characteristics. The third limitation is the heterogeneity of the elderly bipolar group which probably included patients suffering from early and late onset BD indeed these 2 subtypes have known differences regarding their clinical features and outcomes. Moreover, the patients who are in their 
fifties are grouped into the young BD group in the present research, but they could also have been grouped into the elderly BD group, with possibly different results. Finally, the time frame of data collection is rather long. It cannot be excluded that changes in medical practices and medical management of BD patients could have changed the risk of hospitalisation in younger and/or older patients during that period. However, the risk is the same for the two groups of patients.

Despite these limitations, our findings confirm that BD in old age remains a severe disease requiring longer hospitalisations than for BP in younger patients. Future prospective studies are needed to better understand the origin of these differences, such as physical or cognitive comorbidities. This study highlights the rise in hospitalisations of elderly BD patients, logical consequence of the aging process of western populations. Moreover, it would be important to find alternatives to limit long hospitalisations, which are deleterious in these populations.

\section{Role of Funding Source}

This study was not funded by external funding source.

\section{Conflict of Interest}

The authors do not have any conflict of interest.

\section{Acknowledgements}

The authors would like to thank the Vinatier Hospital for making it possible to undertake this study.

\section{References}

Bauer, M., Unützer, J., Pincus, H. A., \& Lawson, W. B. (2002). Bipolar Disorder. Mental Health Services Research, 4, 225229. http://dx.doi.org/10.1023/A:1020968616616

Blackburn, I. M., Ashworth, C. M., \& Loudon, J. B. (1977). A New Scale for Measuring Mania. Psychological Medicine, 7 , 453-458. http://dx.doi.org/10.1017/S0033291700004438

Cassano, G. B., McElroy, S. L., Brady, K., Nolen, W. A., \& Placidi, G. F. (2000). Current Issues in the Identification and Management of Bipolar Spectrum Disorders in "Special Populations”. Journal of Affective Disorders, 59, S69-S79. http://dx.doi.org/10.1016/S0165-0327(00)00180-4

Coryell, W., Turvey, C., Endicott, J., Leon, A. C., Mueller, T., Solomon, D., \& Keller, M. (1998). Bipolar I Affective Disorder: Predictors of Outcome after 15 Years. Journal of Affective Disorders, 50, 109-116. http://dx.doi.org/10.1016/S0165-0327(98)00043-3

Depp, C. A., Jin, H., Mohamed, S., Kaskow, J., Moore, D. J., \& Jeste, D. V. (2004). Bipolar Disorder in Middle-Aged and Elderly Adults: Is Age of Onset Important? The Journal of Nervous and Mental Disease, 192, 796-799. http://dx.doi.org/10.1097/01.nmd.0000145055.45944.d6

Gildengers, A. G., Butters, M. A., Seligman, K., McShea, M., Miller, M. D., Mulsant, B. H., et al. (2004). Cognitive Functioning in Late-Life Bipolar Disorder. The American Journal of Psychiatry, 161, 736-738.

http://dx.doi.org/10.1176/appi.ajp.161.4.736

Gonzalez-Pinto, A. M., Dardennes, R., de Zélicourt, M., López, P., Oliveros, R.G., Vieta, E., Barbeito, S., Echevarria, E., \& Fagnani, F. (2010). In-Patient Care Costs of Patients with Bipolar I Disorder: A Comparison between Two European Centers. Journal of Affective Disorders, 121, 152-155. http://dx.doi.org/10.1016/j.jad.2009.05.010

Hirschfeld, R. M. A., Calabrese, J. R., Weissman, M. M., Reed, M., Davies, M. A., Frye, M. A., et al. (2003). Screening for Bipolar Disorder in the Community. Journal of Clinical Psychiatry, 64, 53-59. http://dx.doi.org/10.4088/JCP.v64n0111

Kessing, L. V. (2006). Diagnostic Subtypes of Bipolar Disorder in Older versus Younger Adults. Bipolar Disorder, 8, 56-64. http://dx.doi.org/10.1111/j.1399-5618.2006.00278.x

Oostervink, F., Boomsma, M. M., Nolen, W. A., The EMBLEM Advisory Board (2009). Bipolar Disorder in the Elderly; Different Effects of Age and of Age of Onset. Journal of Affective Disorders, 116, 176-183. http://dx.doi.org/10.1016/j.jad.2008.11.012

Ösby, U., Tiainen, A., Backlund, L., Edman, G., Adler, M., Hällgren, J., Sennfält, K., van Baardewijk, M., \& Sparen, P. (2009). Psychiatric Admissions and Hospitalization Costs in Bipolar Disorder in Sweden. Journal of Affective Disorders, 115, 315-322. http://dx.doi.org/10.1016/j.jad.2008.09.011

Pini, S., de Queiroz, V., Pagnin, D., Pezawas, L., Angst, J., Cassano, G. B., \& Wittchen, H.-U. (2005). Prevalence and Burden of Bipolar Disorders in European Countries. European Neuropsychopharmacology, 15, 425-434. 
http://dx.doi.org/10.1016/j.euroneuro.2005.04.011

Sajatovic, M., Bingham, C. R., Campbell, E. A., \& Fletcher, D. F. (2005). Bipolar Disorder in Older Adult Inpatients. The Journal of Nervous and Mental Disease, 193, 417-419. http://dx.doi.org/10.1097/01.nmd.0000165296.50985.a8

Sajatovic, M., Bingham, C. R., Campbell, E. A., \& Fletcher, D. F. (2006). Factors Associated with Functional Decline of Hospitalised Older Persons Following Discharge from an Acute Geriatric Unit. Annals Academy of Medicine Singapore, 35, 17-23.

Wu, H.Y., Sahadevan, S., \& Ding, Y.Y. (2004). Age-Related Modifiers of Clinical Presentation and Health Service Use among Veterans with Bipolar Disorder. Psychiatric Services, 55, 1014-1021. http://dx.doi.org/10.1176/appi.ps.55.9.1014 
Scientific Research Publishing (SCIRP) is one of the largest Open Access journal publishers. It is currently publishing more than 200 open access, online, peer-reviewed journals covering a wide range of academic disciplines. SCIRP serves the worldwide academic communities and contributes to the progress and application of science with its publication.

Other selected journals from SCIRP are listed as below. Submit your manuscript to us via either submit@scirp.org or Online Submission Portal.
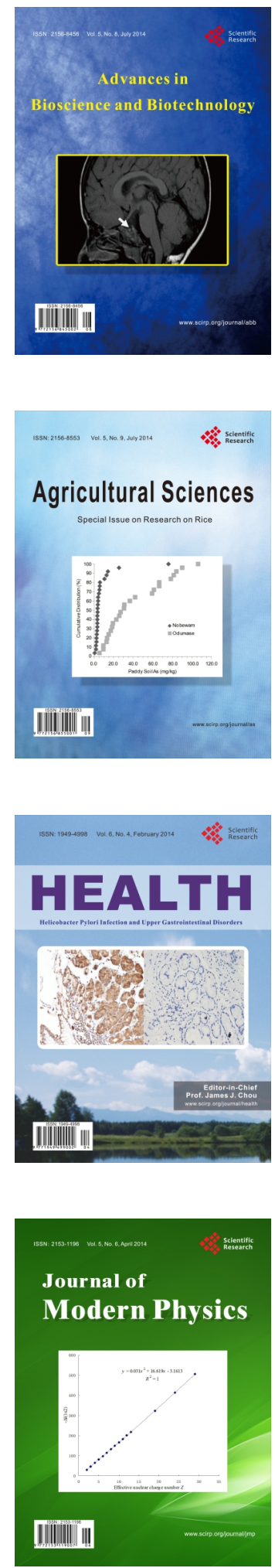
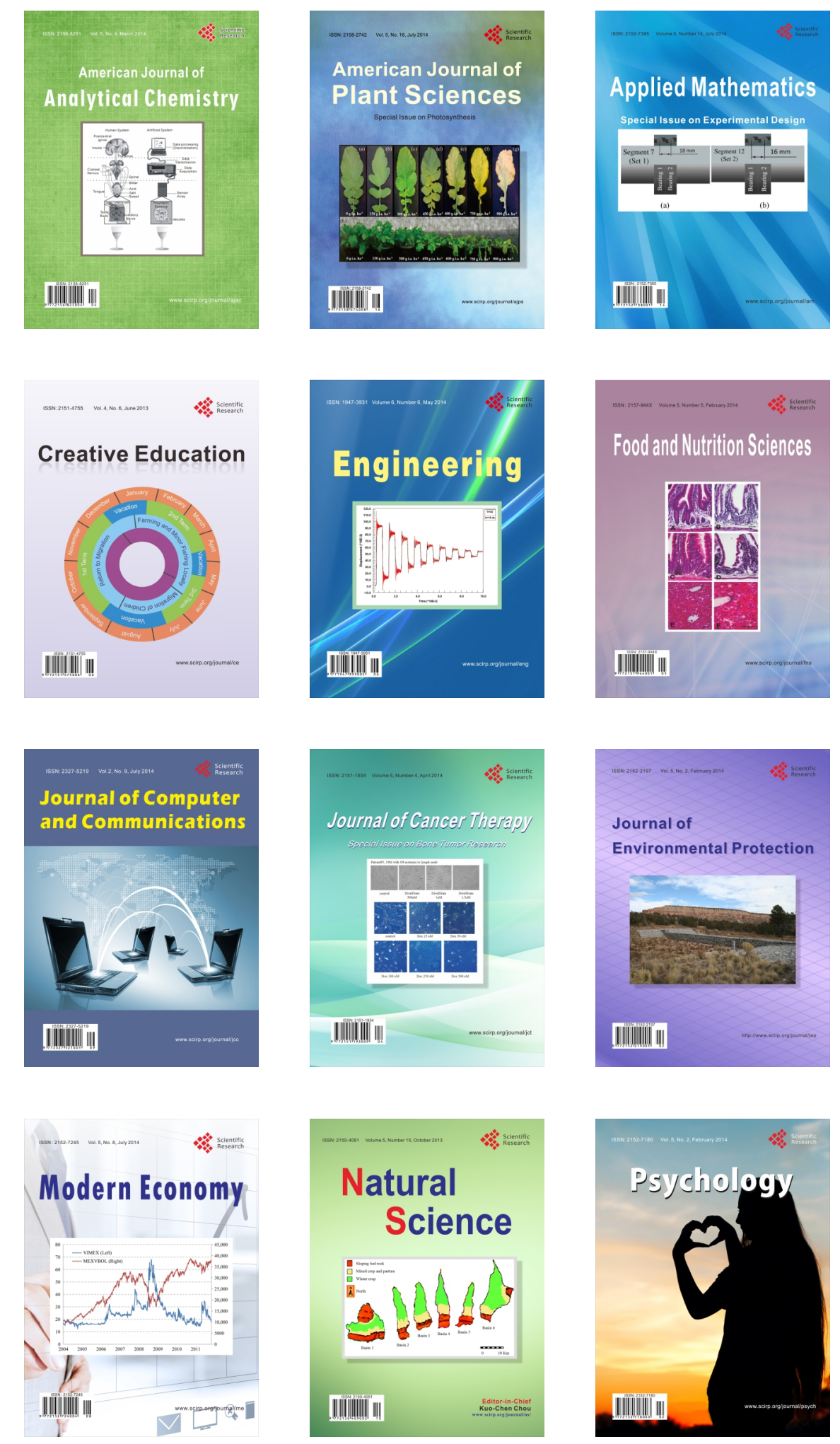